\title{
绿色建筑设计理念在居住区建筑设计中的融合应用
}

\author{
张 磊* \\ 山东东瑞规划建筑设计院有限公司, 山东 274300
}

摘 要: 随着人们环保意识越来越强, 对建筑的要求也有了新的变化, 人们对建筑设计的环保性越来越重视。在 居住区的建筑设计中应用绿色设计理念, 可以有效优化资源的配置, 提高建筑的舒适度和美观度, 为居民提供健康和 谐的生活环境。本文主要讲述了绿色建筑的设计原则以及绿色建筑设计理念在居住区设计中的应用。

关键词：绿色建筑；设计理念；居住区；融合应用

\section{The Fusion Application of Green Building Design Concept in Residential Building Design}

\author{
Lei Zhang*
}

Shandong Architectural Planning and Design Institute Limited Dawnrays, Heze 274300, Shandong, China

\begin{abstract}
With the increasing awareness of environmental protection, there are new changes in the requirements of architecture. People pay more and more attention to the environmental protection of architectural design. The application of green design concept in the architectural design of residential areas can effectively optimize the allocation of resources, improve the comfort and beauty of buildings, and provide healthy and harmonious living environment for residents. This paper mainly describes the design principles of green building and the application of green building design concept in residential area design.
\end{abstract}

Keywords: Green building; Design concept; Residential area; Fusion application

\section{一、前言}

绿色建筑不仅仅是对绿化的应用, 其更重要的意义在于优化资源的配置, 使建筑与周围的自然环境达到协调统

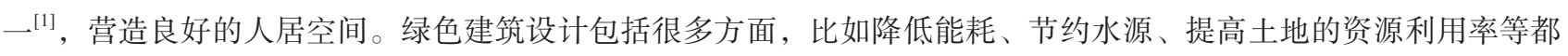
属于绿色设计。绿色建筑设计要求建筑在设计和建设的过程中, 要充分利用创新、节能、环保的材料、技术、手 段，最大限度地减少建筑对周围生态环境的破坏，保证建筑的品质。

\section{二、绿色建筑的设计原则}

绿色技术的诞生在于减少对现有物资和资源的消耗, 并将所使用的建筑及生活资料进行循环利用, 确保其能够实 现效益最大化 ${ }^{[2]}$ 。因此体现在以下几部分。

（一）节约能源

其中即包含水、电暖、燃气等生活必需品, 同时还涵盖对于雨水、风力等自然资源进行引用, 充分利用其使用持 久性的优势。

\section{(二) 减少环境破坏}

特别是随着建筑项目开工，产生了对包括交通秩序、生活习惯等人文社会，以及土壤、植被等自然条件的损害。 绿色技术的本质在于降低对其破损程度，来缓解人与自然环境中的矛盾冲突。

(三) 保证居住体验

在进行居住区的建筑设计时, 首先要考虑到居民对于居住的相关需求, 再运用绿色的设计理念对建筑的内部环境 和外部环境进行设计, 保证居民能够有较好的居住体验。在图 1 中可以看出, 人们对于建筑最主要的需求就是健康舒

*通讯作者: 张磊, 1989年10月, 男, 汉族, 山东菏泽人, 山东东瑞规划建筑设计院有限公司, 中级工程师, 大 学本科。研究方向: 建筑设计。 
适、生活便利, 任何人都不想生活在一个脏乱差或者危险的居住环境中, 要想保证居住体验, 就需要对建筑周围的自 然条件进行充分的研究和分析, 包括对地质、气候、自然灾害等因素进行综合考虑, 在此基础上制定科学的设计方 案，使设计方案具有较强的可行性，保证人们的居住环境是安全的。
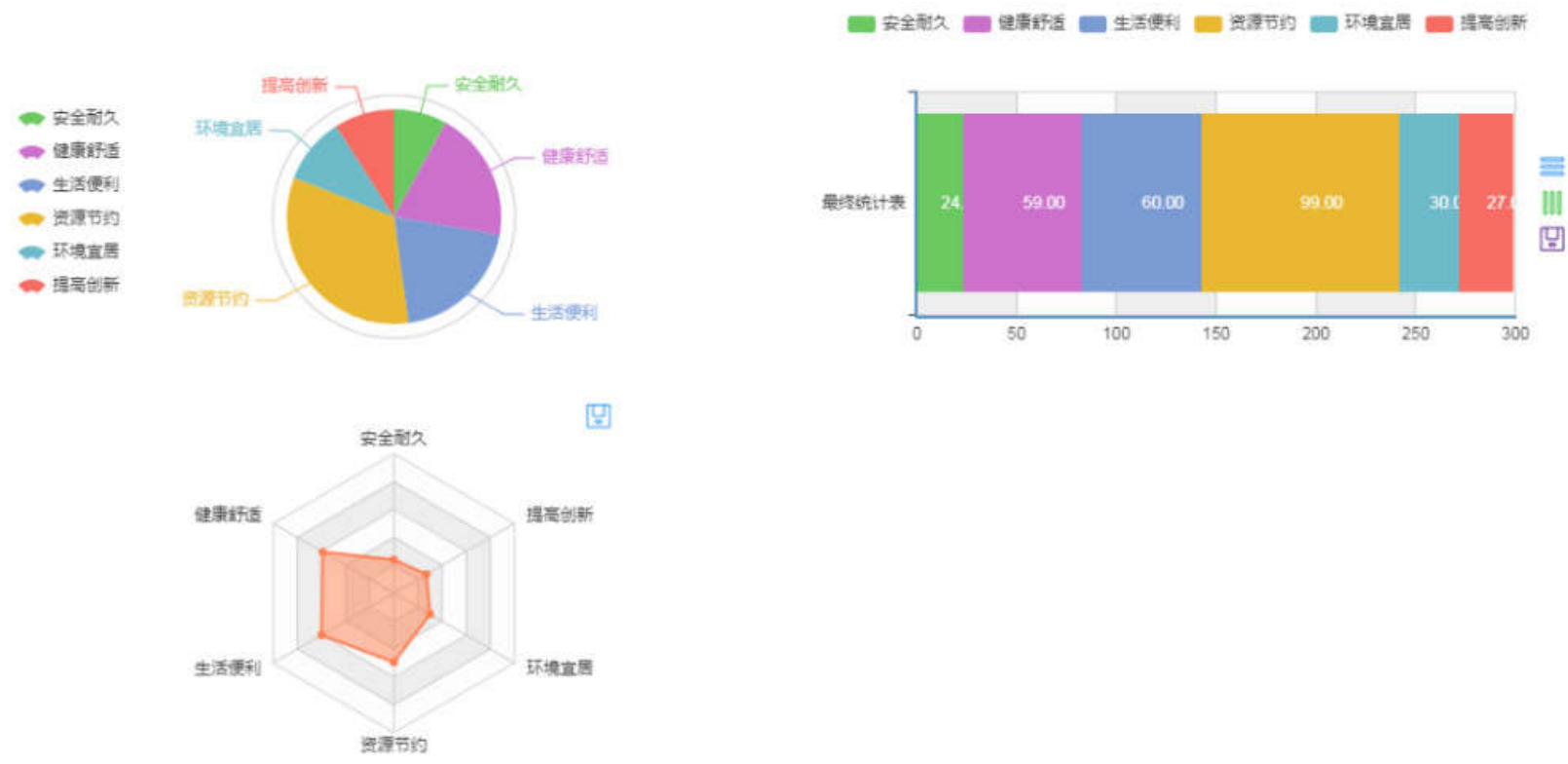

图1 绿色建筑的策划与评价系统

建筑的风格和当地的人文与环境相结合, 形成良好的建筑景观, 提高人们的审美体验。同时也要加强对这些自然 生态因素的利用, 能够利用当地的先天优势提高建筑的居住体验, 比如利用自然风、采光以及当地的材料等来进行建 筑设计，不仅能够使住户与大自然亲密接触，还能够从而提高各种资源的利用率，减少浪费和污染。

（四）提高生态效益

在绿色建筑的设计中要尊重生态效益的原则, 促使建筑和生态环境能够和谐发展。建筑的设计要考虑到建设区域 的水文、地形以及植被, 并进行合理地利用和保护, 保证人与自然和谐共存 ${ }^{[3]}$ 。合理地利用当地的资源, 并应控制有 害物质的产生与排放，在设计中要充分考虑到这方面的因素，提高生态效益。

（五）节约资源

建筑设计工作决定着以后的施工方式和施工管理, 所以在设计之初就要运用绿色的理念对设计方案进行优化, 以 便对施工进行科学的管理, 减少各种资源的浪费, 提高资源的利用率, 同时也注重选择一些绿色的施工材料和施工工 艺, 保证建筑设计的环保性。

(六) 节能设计

在建筑的设计中, 要进行节能方面的设计。这就需要设计人员积极落实国家的相关政策和规定, 按照节能的标准 来进行设计。选择节约能源的施工技术和设备, 加强施工过程管理, 多运用可再生的能源, 避免能源的浪费。

\section{三、绿色建筑设计理念在居住区设计中的应用}

（一）在整体平面布局中的应用

1. 要做好建筑的选址工作, 将居住区安排在合适的地理位置。建设用地要从整体上进行考虑, 保证布局的科学 性，利用好周围的坡地和荒地，避免占用农业用地。

2. 在平面设计之前要对建筑用地周围的环境进行深人地分析, 尤其是在地形方面, 最好把建筑和地形结构结合起 来进行布局，利用好周围的地形，减少施工作业，避免对环境的破坏 ${ }^{[4]}$ 。

3. 合理布置建筑的角度、朝向、道路以及相邻建筑之间的间距, 尽可能使用自然通风和光照。要做到这一点, 设 计人员要对建筑用地的日照情况、人射角度等进行严密的计算, 从而算出最佳的建筑平面角度以及建筑朝向, 还要根 据夏季的主导风向来保证建筑整体具有良好的通风情况。

4. 对单体建筑进行设计时，要根据地下水位、地质因素、地形等情况设计合理的地下空间。 
5. 要使建筑成为宜居的绿色建筑, 还要保证其拥有完备的配套设施, 在规划配套设施时, 要根据建设区域周边的 情况对自身进行合理布局。配套设施的建设要秉持为住户服务的原则，提高配套设施的公用性。

\section{(二) 单体设计}

在对建筑的内部进行设计时，要注重对户型的设计，保证内部空间能够被合理地分割，保证室内的通风采光良 好, 并且有利于保证室内的温度以及具有较好的隔音效果。在平面设计时运用绿色的设计理念, 将室内划分出明显的 分区, 并使这些分区的布置合理。比如, 卧室是休息的区域, 书房是需要集中精力的区域, 这两部分区域就不能和厨 房、卫生间等能够产生噪音的房间放在一起; 起居室要远离电梯间, 并设计好房间内的动线; 厨房与卫生间进行集中 设置，便于安装各类管道，还有利于排风设施的安装，从而减少工程量，降低生活污染。

在立面设计时运用绿色的设计理念, 要注意建筑的造型要简约、美观、大方, 控制好外墙的开窗比, 节省一些不 必要的装饰性材料和构件的应用, 控制好建筑的体型系数。建筑的体型系数如果过大, 在后期的使用中会产生大量的 能耗, 反之, 如果建筑的体型系数相对较小则有利于节省能源。在设计时要尽量减少建筑外墙的面积, 严格限制居住 区建筑的层高, 建筑的外立面要建设呈规则形状的平面。除此之外, 也要对门窗的位置进行科学的设计, 在冬季增强 建筑的保温功能, 在夏季增强建筑的通风散热功能 ${ }^{[[]}$。

\section{(三) 室内设计}

绿色的室内设计要求建筑要保证自然采光能够更多的照射在人们经常活动的区域; 采用合理的照明设计, 将局部 照明和整体的照明效果结合起来, 尽量选用高效节能的灯具和电器; 合理设计室内的温度、湿度调节系统, 使室内的温 度与湿度能够满足人们对于舒适生活的要求; 建立合理的防辐射结构, 保证室内的舒适性; 选择隔音效果好、环保的材 料, 减少噪音污染, 遵守隔音设计的相关规定; 提高建筑的自然通风效果, 避免出现霉菌滋生、串气、结露等现象 ${ }^{[6]}$ 。

（四）建筑外侧结构的节能设计

在建筑的外侧我们通常会运用到大量的建筑材料, 建筑外侧是建筑体进行能源转换的主要部分, 所以说建筑材料 的选择对于节约能源来说十分重要。建筑的外侧结构和建筑材料能够收集大量的自然能源, 在绿色设计理念下, 需要 将这些自然能源进行有效地利用, 最好具有一定的气候调节作用, 防止建筑给自然气候带来更多的不利影响, 如图2 所示，将太阳能板和建筑一体化的阳台，能够充分利用建筑的外侧结构吸收太阳能，完成能源的收集 ${ }^{[7]}$ 。

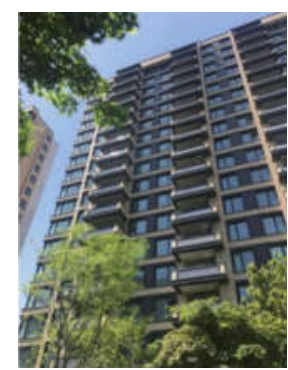

图2 太阳能板和建筑一体化的阳台

做好节能设计主要可以从以下几个方面做起。

1. 要选择性能良好的外墙材料, 比如选择隔热砖而非黏土砖。

2. 要多应用专业的镀膜的玻璃, 减少玻璃的导热系数, 优化室温环境。

3. 增强门窗的封闭功能, 防止热量交换带来的室温变化。

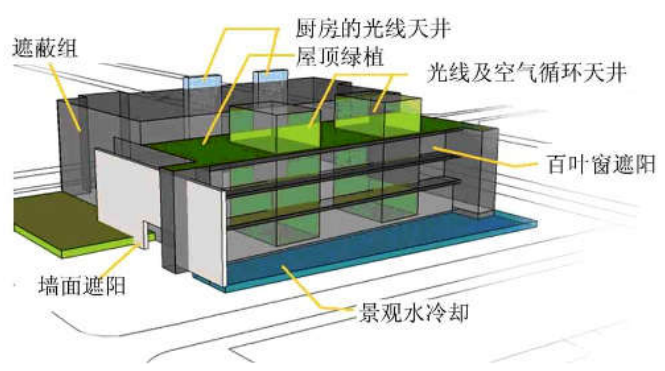

图3 绿色技术应用简图 
4. 在选择遮阳设备时, 在保证结构稳定性和强度的情况下, 选择那些相对比较轻便的、而且能够进行自由调整的 设备, 如图3中的绿色建筑使用的百叶窗, 相对来说就比较轻便而且能够进行自由的调整, 使居住区的建筑居住起来 更加舒适。

(五) 室外的绿化设计

在建筑的周围规划绿化带能够使人的居住环境更加贴近自然, 而且绿化带还能够起到吸烟滞尘、降低噪音、美化 环境等作用 ${ }^{[8]}$ 。比如栽植行道树、花坛、绿地等, 还可以安装反射率较高的居住区步道铺设材料, 建设地面对太阳能 的吸收。

（六）利用好可再生的资源

绿色建筑设计注重对资源的优化配置和利用, 进行绿色设计时要充分利用好当地的可再生能源, 比如太阳能、地 热能、水资源等。比如安装雨水回收系统, 把收集的雨水用来浇灌绿地; 安装太阳能广电系统, 收集太阳能进行发 电, 为居民提供生活用电, 节约能源; 运用植物系统, 吸收空气中的有害物质, 保护人们的身体健康; 利用太阳能电 池所收集的能源进行采暖与照明 ${ }^{[0]}$ 。

\section{四、结束语}

居住区的建筑设计对于人们的生活具有十分重要的影响, 相关的建筑设计人员一定要根据绿色建筑的设计原则, 在 设计工作中秉持保证住户的居住体验、提高生态效益、有助于节约资源和能源的原则进行对建筑的设计。在建筑的整体 平面布局、单体设计、室内设计、建筑外侧结构的节能设计、室外的绿化设计等方方面面注重绿化设计理念的融人, 充 分利用好可再生的资源, 保证所设计项目的环保性。总而言之, 绿色建筑设计理念带给人的影响是方方面面的, 相关的 设计者一定要加强先进绿色理念的应用, 为人们提供更好的居住环境, 促进人和自然的和谐共存与协调发展。

\section{参考文献:}

[1]张爱国.绿色建筑设计理念在居住区设计中的应用分析[J].建筑工程技术与设计, 2021(9):720.

[2]彭荣强.简析绿色建筑设计理念在居住区设计中的应用 [J].中国住宅设施, 2020(11):45-46.

[3]喻梦茹.夏热冬暖南区居住区建筑设计中的绿色优化要点探析[J].建材与装饰, 2017(23):74-75.

[4]任禄. 夏热冬冷地区的居住区绿色建筑适宜技术研究——合肥市某小区为例 [J]. 工程技术研究, 2017(9):46-47.

[5]王元季.对于居住区绿色建筑设计阶段声环境预测方法的分析和研究 [J].城镇建设, 2021(5):279.

[6]供强,朱丽.保障房绿色建筑设计中的增量成本构成一一廈门洋塘居住区为例 [J].建筑节能, 2014(1):97-99.

[7]吴剑春, 张安安,朱子根.对于居住区绿色建筑设计阶段声环境预测方法的分析和研究 [J].绿色建筑, 2010,2(4):47-49.

[8]王竹,魏秦,贺勇.地区建筑营建体系的“基因说”诠释——黄土高原绿色窑居住区体系的建构与实践 [J]. 建筑师, 2008(1):29-35.

[9]李玉洁.中原地区养老机构绿色建筑居住环境质量分析[J].美与时代・城市, 2021(1):30-31. 